Preface

\section{Lower Gastrointestinal Bleeding}

David E. Rivadeneira, MD, MBA, FACS, FASCRS ${ }^{1,2,3}$

${ }^{1}$ Department of Surgery, Zucker School of Medicine at

Hofstra/Northwell, Hempstead, New York

${ }^{2}$ Surgical Strategic Initiatives at Northwell Health, Woodbury, New York

${ }^{3}$ Colorectal Surgery and Surgical Services, Huntington Hospital, Huntington, New York

Clin Colon Rectal Surg 2020;33:3-4.

In this current issue of Clinics of Colorectal Surgery, we tackle the vexing clinical scenario of lower gastrointestinal bleeding. We have assembled an incredibly experienced and renowned colorectal surgeons which have authored the most current management of gastrointestinal bleeding.

Included in this edition, we provide a concise review of the most common causes of gastrointestinal bleeding including upper gastrointestinal sources, in addition, the authors provide the most current diagnostic modalities and nonsurgical therapeutic options available.

Attention to special considerations have also been addressed by the authors, including dealing with the anticoagulated patient with gastrointestinal bleeding and the ever de-

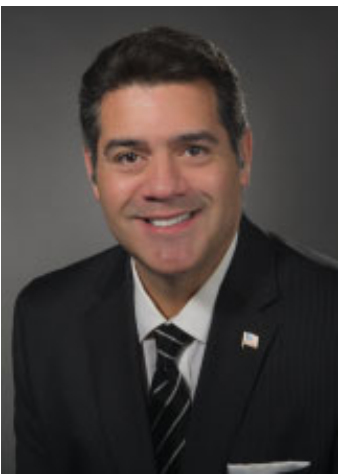

David E. Rivadeneira, MD, MBA, FACS, FASCRS

manding bleeding from the small intestine.

The authors also provide an exceptional review of surgical options and approaches including the timing and extent of surgery.

I am honored to have assembled this phenomenal group of colorectal surgeon authors, and I will be grateful forever for the time they spent on this project, their professionalism, and availability in making this a successful endeavor.

I am truly grateful to Dr. Steele for the invitation to be the guest editor of this edition and have always appreciated his guidance and patience.

Address for correspondence David E. Rivadeneira, MD, MBA, FACS, FASCRS, 321 B Crossways Park Drive, Woodbury, NY 11797 (e-mail: Drivadeneira@ northwell.edu).
Issue Theme Lower GI Bleeding; Guest Editor: David E. Rivadeneira, MD, MBA, FACS, FASCRS
Copyright $\odot 2020$ by Thieme Medical Publishers, Inc., 333 Seventh Avenue, New York, NY 10001, USA. Tel: +1(212) 584-4662.
DOI https://doi.org/

10.1055/s-0039-3400279. ISSN $1531-0043$. 